\title{
Real estate private equity: the case of US unlisted REITs*
}

\author{
John Corgel \\ Cornell University \\ Scott Gibson \\ The College of William and Mary
}

\begin{abstract}
Purpose - The purpose of this paper is to demonstrate how fixed-share prices, as a structural flaw in private equity funds targeted to small-unit investors, economically disadvantages those investors in favor of sponsors.

Design/methodology/approach - The theoretical model incorporates fixed share prices with continuous investment opportunity and evaluates the wealth transfer from long-term investors to marketing affiliates and soliciting dealers in the form of fees paid on the sale of shares to follow-on investors.

Findings - This result holds in the presence of high-payout dividend policy that attempts to compensate for wealth transfer.

Research limitations/implications - Should share prices be marked-to-market using real estate appraisals or another method, the unlisted REIT and related offerings, such as tenant-in-common funds, will be profitable for sponsors without economically disadvantaging long-term investors. Practical implications - The findings from this research are useful to fund sponsors who design real estate investment products for small-unit investors. These products may retain the advantageous characteristics of existing products while eliminating the disadvantageous features. Originality/value - This is the first academic research on private equity capital raised from small-unit investors.
\end{abstract}

Keywords Real estate, Equity capital, Property finance Paper type Research

\footnotetext{
* The authors wish to acknowledge the assistance provided by Deborah Froling of Hirschler Fleischer and Glen Fuller of Mackenzie Patterson Fuller, Inc., who provided critical input about how the Unlisted REIT business operates.
} 
paper

\section{Introduction}

Private equity funding of institutional-grade commercial real estate in the US has historically come from wealthy individuals and pension funds. These sources remain dominate today as evidenced by the recent wave of real estate public-to-private transactions. Small-unit investors were provided the opportunity to purchase shares in publicly-traded portfolios of commercial real estate in 1960 in the US when the first REIT law was enacted and now in many countries throughout the world as the REIT concept proliferates.

During the early 1990s, real estate fund sponsors in the US began raising equity for commercial real estate investment using broker-dealer channels. Replicating dividend networks established by mutual fund groups, sponsors offer real estate investment programs to the population of mostly small-unit investors who rely on the services of financial planners. Sponsors using broker-dealer networks to raise equity capital begin as private companies. While sometimes referred to as "private REITs", a select group of these companies and the mini-industry that now surrounds them, prefer the title "unlisted REIT" because sponsors follow the SEC's rules for publiclytraded REITs, but do not list shares on exchanges[1]. The success of the unlisted REIT approach is evidenced by the relatively high volume of equity flows to these companies, sometimes resulting in near-parity with inflows to publicly-traded REITs. During 2003, for example, the unlisted REIT group, raised $\$ 7$ billion through broker-dealer channels while all publicly-traded REITs raised $\$ 8.1$ billion through public stock offerings [2]. Similar brokerdealer networks are now used in the in US to facilitate tax-free exchanges through tenant-in-common (TIC) funds [3].

\subsection{Unintended consequences for unlisted REIT investors}

The emergence of unlisted REITs as highly visible participants in the commercial real estate markets may be the result of small-unit investors rationally responding to the attractive investment opportunities offered by these firms. Yet, some members of the financial press and executives of publicly-traded REITs question the methods used by unlisted REITs (Smith, 
2003a, b; Fitch, 2003; Ostrowski, 2004; Farrell, 2006). Criticisms center on the adverse effects of aggressive fees (i.e. often 10 percent to 15 percent) deducted from investor contributions and paid to financial planners and sponsors. To a lesser extent, criticisms focus on structural characteristics of the ongoing contractual relation between investors and sponsors.

Unlisted REITs sell shares at a price (i.e. typically \$10) that either remains fixed or may be modestly adjusted throughout investors' holding periods [4]. This feature differentiates unlisted REITs from publicly-traded REITs and is frequently cited by sponsors and broker-dealers as an advantage of the unlisted REIT structure. Small-unit investors, as the argument goes, find the volatility of public REIT prices undesirable, and therefore feel more secure with a relatively high dividend paying investment in which the share price remains constant. As Fitch (2003) notes, the apparent advantage of a fixed-price structure may instead represent a disadvantage to investors because they cannot share in appreciation without asset liquidation or company sale.

In this paper, we argue that the fixed price feature of unlisted REITs potentially has more serious negative financial consequences for investors who contribute capital early in the funding cycle. After controlling for dividend payout, we demonstrate that fixed share prices with continuous investment opportunity adversely affects long-term investors by transferring wealth to unlisted REIT affiliates and soliciting dealers in the form of fees paid on the sale of shares to follow-on investors. This contractual feature represents a flaw in the unlisted REIT structure with several detrimental consequences. These consequences, as we argue, place in jeopardy the longterm viability of unlisted REITs that rely on fixed share price structures. Higher dividend payout moderates the wealth transfer from initial investors, but also exacerbates the financial stress experienced by unlisted REITs that distribute more money than current cash flow, as we show later in the paper. Should unlisted REITs elect to periodically mark share prices to market using either real estate appraisals (following commingled funds) or some other method, the unlisted REIT business will continue without economically disadvantaging long-term investors.

The balance of this paper is organized as follows. Section 2 presents the institutional details about the unlisted REIT business. We develop an economic modeling structure in section 3 . This model allows for examinations of investment returns and the profit opportunities available to two classes of 
investors - long-term investors and follow-on investors. In section 4, we use the model along with a set of assumed parameter values to study the outcomes for both classes of investors when follow-on investment is prohibited and when follow-on investors operate in a competitive environment. The conclusion, presented in section 5, describes how the fixed share price arrangement creates incentives for continuous selling of unlisted REIT shares, asymmetrical participation in real estate value changes, and the wealth transfer that occurs from long-term investors to unlisted REIT affiliates and soliciting dealers. We also make recommendations for altering the unlisted REIT structure.

\section{Institutional detail}

Because no published papers have appeared on unlisted REITs, we provide selected institutional details about how these businesses operate [5]. As shown in Figure 1, the ownership entity is embedded in a fairly complex network of relationships with service providers and regulators. The chain that connects REITs to investors is our main interest. This chain begins with the establishment of an in-house broker-dealer affiliate that develops contractual relationships with national and regional managing dealers (e.g. A.G. Edwards, UBS Warburg, and Paine Webber). Local financial planners acting as soliciting dealers with or without affiliations to these national and regional brokerdealers then sell investment programs of unlisted REITs to the public. Managing brokers may acquire due diligence reports from third-party companies that inform about the capability, competency, and integrity of unlisted REIT sponsors prior to agreeing to sell their investment programs.

Individuals invest as little as $\$ 1,000$ after being given the prospectus of an unlisted REIT. The investment of $\$ 1,000$ is reduced by the fees owed to the network including the in-house broker-dealer company. For example, with a 10 percent fee, $\$ 900$ is actually invested in real estate. Investment programs qualify as securities and therefore must conform to the requirements of the SEC, NASAA (in most states), and NASD. Also, the actions of broker-dealers in their relations with the public must conform to NASAA requirements and are regulated by NASD. External advisors - usually subsidiaries of unlisted REITs - carry out day-to-day operations including relationship management with regulators, attorneys, and accountants [6]. Unlisted REIT prospectuses contain language about how companies will exit their current form to provide investors with a return of capital. Sometime the 
language gives a specific date (i.e. on or before). In other instances the language gives the unlisted REIT considerable flexibility for this exit. As shown in Figure 1, four alternative exit events could occur - private market liquidation of properties, exchange listing, IPO as the combination of exchange listing with public capital infusion, and merger with an existing company. Unlisted REITs may hope to capitalize on a favorable privatemarket-to-public-market arbitrage opportunity during latter stages of the investment period.

Figure 1: Unlisted REIT business and regulatory relationships

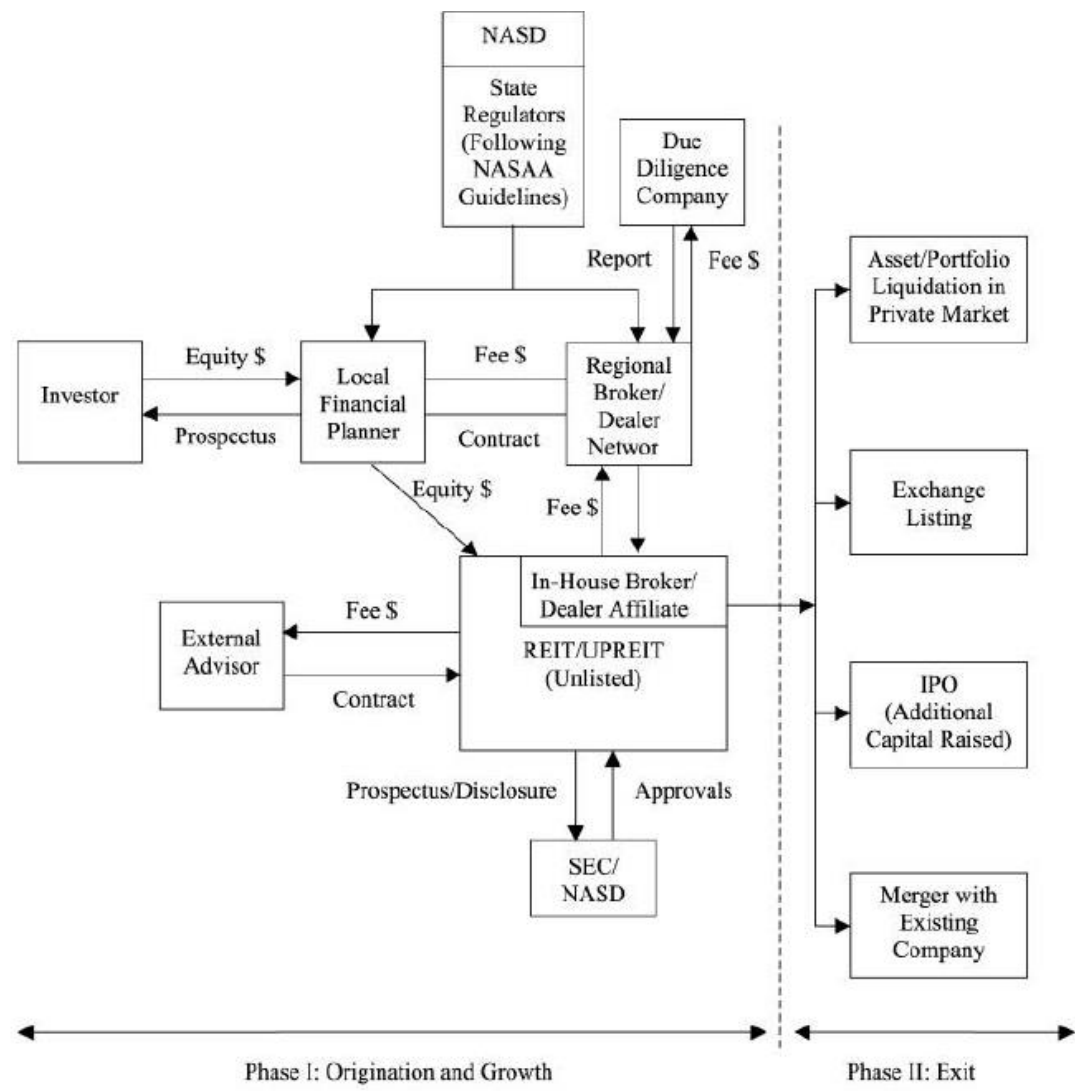

Notes: Three dimensions are portrayed in this figure. First, money flows into the Unlisted REIT, fee payments, and exit strategies are traced. Second, the organizational structure of the Unlisted REIT appears. Third, the regulatory relationships that effect how Unlisted REIT and related entities operate are shown 


\subsection{Investor appeal and criticisms}

Logic suggests that the sizeable flow of equity capital recently moving into unlisted REITs occurred because the investment programs offered by these firms contained features appealing to individual investors. The features touted by proponents as being attractive to investors include:

- High dividend. Unlisted REITs promise an annual dividend of between six percent and 7.75 percent based on capital contributed. During recent years, this dividend payout ratio dominated the dividend from alternative investment programs available through financial planners. As we discuss in section 5 , unlisted REIT payout ratios typically exceed 100 percent of FFO, while listed REIT payout ratios approximate 70 percent of $F F O$.

- Collateral. While individual investors receive no guarantees that dividend payments will continue throughout the planned investment period, they recognize that their money is placed in assets with an active secondary trading market should liquidation become necessary. Also, as sponsoring companies continue to grow larger, a signal of increasing financial strength is sent to investors.

- Return of capital. Although redemption policies are restrictive, the idea of a planned exit written into the prospectus provides assurances to investors that sponsors would execute an exit that will return capital.

- Fixed share prices. Individual investors who are drawn to investing in institutional grade real estate, yet fear the volatility of publicly-traded REIT prices, are provided with the opportunity to place money with high quality real estate companies at fixed share prices.

Critics contend that the costs of features investors find attractive about unlisted REITs relative to publicly-traded REITs seem excessive. The features critics cite as being unattractive to investors include:

- Selling, service, and acquisition fees. The selling, service, and acquisition fees paid to unlisted REIT affiliates and soliciting dealers are typically in the range of ten percent to 15 percent of initial investments, a fee structure some critics view as overly aggressive. Fitch (2003), for example, presents a table showing that the average fee from a $\$ 10,000$ investment in an unlisted REIT equals $\$ 1,358$ 
while a dollar-equivalent trade in comparable publicly-traded REITs costs $\$ 29.95$. Industry representatives counter with the argument that the costs of raising capital through broker-dealer networks exceed the costs of bringing in money through traditional channels (Johnson, 2003).

- Redemption policies and exit strategies. The unlisted REIT sponsors have come under criticisms for restrictive redemption policies and vague exit strategies. The issue of viable exit strategies has, however, been mitigated to a large extent by the successful public listing by Inland Real Estate Company (IRC).

- Fixed share prices. Fixed share prices are listed above as a feature marketed to investors as a benefit. We argue that the fixed share price feature more rightly belongs in the list of unattractive features. As we show in the subsequent analysis, continuingly offering shares at a fixed offer price throughout the investment cycle has significant adverse economic consequences for long-term investors.

\subsection{Perverse dividend policy}

How dividend policy influences the value of firms and cost of equity capital remains one of the more interesting areas of intellectual inquiry in financial economics. Because REITs operate under regulatory constraints regarding dividend payout, REIT data has been used quite frequently to test corporate dividend policy hypotheses [7]. Corgel et al. (1995), from a review of the early literature, finds insufficient evidence to conclude that the dividend-related regulatory constraints distort REIT valuations. The unique controls that the regulated REIT market provides, however, continues to promote research on the subjects of corporate dividends and taxes [8]. Two studies since 1995 specifically address differential dividend payout ratios among REITs. First, Bradley et al. (1998) presents evidence that REIT payout ratios are low with higher expected cash flow volatility in accordance with information-based explanations for dividend policy. In the second paper, Ghosh and Sirmans (2006) tests the hypothesis that ineffective management with respect to share price growth offer higher dividends to appease disgruntled investors. They find that corporate performance explains dividend payout and yield.

None of the traditional explanations for the relatively high dividends 
paid by unlisted REITs during recent years fit the investment circumstances surrounding the emergence of these firms. Insufficient time has passed in the life of unlisted REITs for investors to effectively evaluate either cash flow volatility or the ability of management to increase the values of asset portfolios. We are left with an explanation that the dividend policies of unlisted REITs derive from motives related to rapid asset growth, system fee generation, and the need for a defense mechanism against wealth transfer created by the fixed-share price structure.

\section{Modeling the problem of fixed share prices and wealth transfer}

Our model captures how long-term investors who buy unlisted REIT shares with fixed offer prices are affected by the opportunistic actions of follow-on investors. Long-term investors in the model remain passive, buying shares of the unlisted REIT at origination and holding them until the unlisted REIT executes an exit either by liquidating in the private market, listing on a public exchange, or merging with another company. Follow-on investors behave in active ways, choosing whether or not to buy shares at a fixed offer price after properties held by the Unlisted REIT experience changes in values. Structuring the model in this way allows us to concentrate on the factors that enter into follow-on investors' decisions and isolate how their trading affects long-term investors' return on unlisted REIT investments.

\subsection{Model timeline}

Our two-date model ( $t=0$ and $t=1)$ includes a group of long-term investors who buy shares in an unlisted REIT at $t=0$ and a group of follow-on investors who have the opportunity to buy shares at $t=1$. Table I presents the investment timeline. Referring to Table I, one can think of the interval between the beginning of $t=0$ and the end of $t=1$ as a multi-year period over which dividends and real estate returns accumulate.

At $t=0$, the unlisted REIT sells $\boldsymbol{n}_{\boldsymbol{0}}$ shares at a price $\boldsymbol{p}_{\boldsymbol{o}}$ per share to long-term investors, raising total gross proceeds of $\boldsymbol{n}_{0} \boldsymbol{p}_{0}$. After unlisted REIT affiliates and soliciting dealers are paid selling, service, and acquisition fees equal to $f$ percent of gross proceeds, net proceeds of $(1-f) n_{o} p_{o}$ are invested in real estate.

Between $\mathrm{t}=0$ and $\mathrm{t}=1$, real estate generates a market return 
represented by the distribution $\widetilde{R}$, which is publicly known at $\mathrm{t}=0$. The realized return:

$r \in[\underline{r}, \bar{r}]$

is publicly known at $\mathrm{t}=1$, denotes the realization of $\tilde{R}$. The real estate return represents a combination of operating cash flow and either capital gain or loss between $t=0$ and $t=1$. We also assume that between $t=$ 0 and $t=1$, long-term investors accrue dividends, payable at $t=1$, at a rate of $\mathrm{d}$ percent of their original investment.

At $\boldsymbol{t}=1$, real estate generates a rate of return $\boldsymbol{r}$, resulting in unlisted REIT assets of $(1+r)(1-f) n_{0} p_{0}$ before dividends to investors. The unlisted REIT pays cumulative

Table I: Model Timeline

\begin{tabular}{|c|c|c|}
\hline $\begin{array}{l}\text { Registration } \\
t=0\end{array}$ & $\begin{array}{l}\text { Time } \rightarrow \\
t=0 \text { to } t=1\end{array}$ & $\begin{array}{l}\text { Exit } \\
t=1\end{array}$ \\
\hline $\begin{array}{l}\text { Unlisted REIT completes } \\
\text { registration requirements to sell } \\
\text { securities }\end{array}$ & $\begin{array}{l}\text { Unlisted REIT experiences a } \\
\text { return on its real estate }\end{array}$ & $\begin{array}{l}\text { Long-term investors are paid } \\
\text { dividend }\end{array}$ \\
\hline $\begin{array}{l}\text { Long-term investors buy unlisted } \\
\text { REIT shares }\end{array}$ & & $\begin{array}{l}\text { Follow-on investors have the } \\
\text { opportunity to invest in the } \\
\text { unlisted REIT }\end{array}$ \\
\hline $\begin{array}{l}\text { Initial fees paid to unlisted REIT } \\
\text { affiliates and soliciting dealers }\end{array}$ & & $\begin{array}{l}\text { Unlisted REIT exits its current } \\
\text { market position and is } \\
\text { liquidated with proceeds } \\
\text { distributed to investors }\end{array}$ \\
\hline \multicolumn{3}{|l|}{$\begin{array}{l}\text { Unlisted REIT invests net } \\
\text { proceeds in real estate }\end{array}$} \\
\hline \multicolumn{3}{|c|}{$\begin{array}{l}\text { Note: This table traces the two-date sequence in time beginning when the unlisted REIT successfully } \\
\text { registers to sell securities through the period when the firm executes an exit from its current market } \\
\text { position }\end{array}$} \\
\hline
\end{tabular}

dividends to long-term investors equal to $\boldsymbol{d}$ percent of their original investment of $n_{O} p_{0}$, implying a total dividend payment of $d n_{O} p_{0}$. Follow-on investors are given the opportunity to invest in the unlisted REIT at a price of $p_{1}$ per share. Denoting the number of shares purchased by follow-on investors as $n_{1}$, the total additional investment proceeds after accounting for initial fees equals $(1-f) n_{1} p_{1}$. Thus, after accounting for dividends and net additional investment, the value of unlisted REIT assets equals [ $(1+r)(1-f)$ $-\mathrm{d}] n_{0} p_{0}+(1-\mathrm{f}) n_{1} p_{1}$ and the intrinsic value per outstanding share at $t=1$, $p_{1}^{*}$, is: 


$$
p_{1}^{*}=\frac{[(1+r)(1-f)-d] n_{0} p_{0}+(1-f) n_{1} p_{1}}{n_{0}+n_{1}}
$$

Finally, to bring closure to the model, all investors receive the intrinsic value per outstanding share at $t=1, p$, when the unlisted REIT executes an exit.

\subsection{Implications of a fixed offer price}

In the analysis that follows, we show that the current industry standard of selling unlisted REIT shares at a fixed offer price has important implications for follow-on investors' decisions, and ultimately influences the returns of long-term investors. Selling unlisted REIT shares at a fixed offer price means that the $t=0$ offer price equals the $t=1$ offer price, $p_{0}=p_{1}$, and equation (1) can be rewritten as:

$$
p_{1}^{*}=\frac{[(1+r)(1-f)-d] n_{0} p_{0}+(1-f) n_{1} p_{0}}{n_{0}+n_{1}}
$$

Follow-on investors earn excess profits when the fixed offer price is less than the intrinsic $\boldsymbol{t}=1$ value of a share:

$$
p_{0}<p_{1}^{*}
$$

Using equations (2) and (3), we obtain the inequality describing the conditions under which follow-on investors earn a realized return on the unlisted REIT's real estate in excess of dividends and net of fees:

$$
r>\frac{\left(n_{0}+n_{1}\right) f+n_{0} d}{n_{0}(1-f)}
$$

The left-hand side of equation (4) is increasing in/, the initial fee percentage paid out to unlisted REIT affiliates and soliciting dealers, and in $d$, the cumulative dividend percentage paid out to long-term investors. Intuitively for the unlisted REIT to offer returns in excess of dividends to follow-on investors, real estate must generate returns that exceed the fees and dividends it pays out. 


\subsection{Follow-on investors' investment decision and long-term investors' profit}

Now, we analyze how follow-on investor decisions affect long-term investor profits. Follow-on investors' profit from trading, $\boldsymbol{p}_{\mathrm{F}}$, is the difference between the intrinsic value of shares bought and share offer price:

$$
\pi_{F}=n_{1} p_{1}^{*}-n_{1} p_{1}
$$

Given the assumption of a fixed offer price such that $\boldsymbol{p}_{\boldsymbol{0}}=\boldsymbol{p}_{1}$, equation (2) can be combined with equation (5) to give follow-on investors' profit:

$$
\pi_{F}=n_{1}\left\{\frac{[(1+r)(1-f)-d] n_{0} p_{0}+(1-f) n_{1} p_{0}}{n_{0}+n_{1}}-p_{0}\right\}
$$

Long-term investors' profit,

$\pi_{L}$, includes a gain or loss on the shares held and the dividends received:

$$
\pi_{L}=n_{0}\left[\left(p_{1}^{*}-p_{0}\right)+d p_{0}\right]
$$

By substituting the intrinsic value of shares at $t=1$ under the fixed offer price assumption given by equation (2) into equation (7), we obtain the expanded form for long-term investors' profit:

$$
\pi_{L}=n_{0}\left\{\left(\frac{\left[\left(1+r_{1}\right)(1-f)-d\right] n_{0} p_{0}+(1-f) n_{1} p_{0}}{n_{0}+n_{1}}-p_{0}\right)+d p_{0}\right\}
$$

Profit is a function of the number of shares bought by follow-on investors. At the time of follow-on investors' decision, all variables in equation (8) are determined except $n_{1}$. Thus, the opportunities and constraints regarding the purchase of shares facing follow-on investors' become critical to long-term investors' ultimate profit. We consider alternative assumptions about these opportunities and constraints in the next section.

Throughout this analysis, we supplement the general model with 
numerical values to clarify intuition. Recall that in practice several years may elapse between the unlisted REIT's startup at $\boldsymbol{t}=-$ and exit at $\boldsymbol{t}=1$. The economic magnitude of the parameter values in our numerical example are meant to reflect a several-year period over which dividends and real estate returns accrue. We assume that the real estate return distribution, $\boldsymbol{g}(\boldsymbol{r})$, is uniform and that the following parameter values apply (see Table II).

\section{Investment behaviors of follow-on investors}

We show above that long-term investors' profit is a function of the number of shares bought by follow-on investors, $\boldsymbol{n}_{\mathbf{1}}$. We consider two scenarios: prohibited follow-on investment, and profit maximization under perfectly competitive follow-on investment. In the subsequent analysis of the two scenarios, we denote the equilibrium values of $\boldsymbol{n}_{\mathbf{1}}$ as $\mathrm{m}$ and $\boldsymbol{n}_{\boldsymbol{1}}$, respectively.

\subsection{Follow-on investment is prohibited}

The standard for comparison occurs when the unlisted REIT prohibits new investment at $t=1$ (i.e. a closed-end fund). Without follow-on investment, $n_{1}$ $=0$ and profit equations (6) and (8) reduce to:

$$
\begin{gathered}
\pi_{F}=0, \text { and } \\
\pi_{L}=n_{0} p_{0}[(1+r)(1-f)-1]
\end{gathered}
$$

The expected profit to long-term investors is computed as:

$$
E\left[\pi_{L}^{\prime}\right]=\int_{\underline{r}}^{\bar{r}} n_{0} p_{0}[(1+r)(1+f)-1] g(r) d r
$$

Substituting in the values from the numerical example, long-term investors' expected profit is $E=\$ 237.50$, which translates to a 23.75 percent expected return on their $\$ 1,000$ initial investment (i.e. 100 shares at $\$ 10$ each). The $\$ 237.50$ expected profit serves as a benchmark for the numerical analysis 
when follow-on investment is allowed.

Figure 2 shows long-term investors' return, $\boldsymbol{p i e} L / \boldsymbol{n}_{0} \boldsymbol{p}_{0}$, as a function of the real estate return, $r$. The slope is $(1-f)=90$ percent over the entire range from $r=-25$ percent to $r=100$ percent. Thus, after deducting the initial fees of $f=10$ percent paid to unlisted REIT affiliates and soliciting dealers, long-term investors participate fully in the performance of the real estate regardless of how properties perform.

Table II: The Parameter Values

\begin{tabular}{lcl}
\hline Variable & Numerical value & Variable description \\
\hline$n_{0}$ & 100 & $\begin{array}{l}\text { Number of shares purchased by long-term investors at } \\
t=0\end{array}$ \\
$p_{0}$ & $\$ 10.00$ & $\begin{array}{l}\text { Per share offer price at } t=0 \\
\text { Percentage of gross proceeds paid out as selling, service, } \\
\text { and acquisition fees }\end{array}$ \\
$d$ & $10 \%$ & $\begin{array}{l}\text { Percentage of original investment distributed to long-term } \\
\text { investors as a cumulative dividend }\end{array}$ \\
$\frac{r}{\bar{r}}$ & $18 \%$ & Lower bound of possible real estate return \\
& $-25 \%$ & Upper bound of possible real estate return
\end{tabular}


Figure 2: Long-Term Investors' Return under Prohibited Follow-on Investment

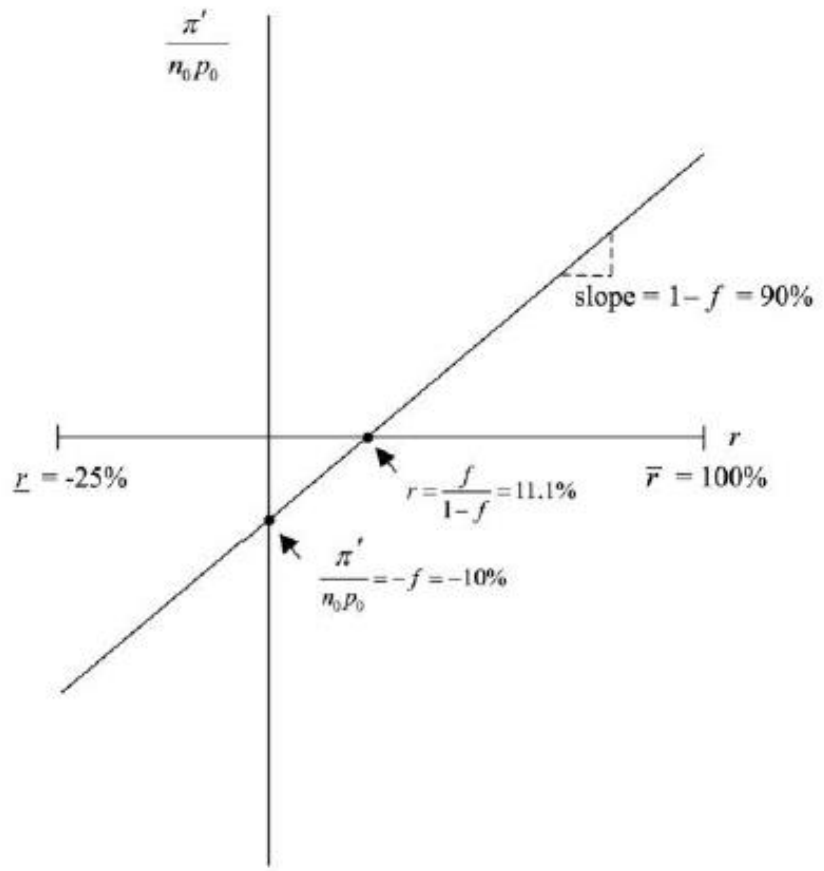

Notes: When follow-on investment is prohibited, long-term investors' return,

$$
\frac{\pi_{L}^{\prime}}{n_{0} p_{0}}=(1+r)(1-f)-1
$$

is a function of the real estate return, $r$. The graph reflects the following parameter values: $n_{0}=100$ shares, ${ }_{0}=\$ 10.00, f=10 \%, d=18 \%, \underline{r}=-25 \%$, and $\bar{r}=100 \%$

\subsection{Perfectly competitive follow-on investment}

Perfect competition assumes unrestricted entry among follow-on investors. When real estate performs poorly and the inequality in equation (4) does not hold for $\boldsymbol{n}_{1}=0$, the offer price exceeds the intrinsic value of shares and follow-on investors do not buy shares. Thus, when real estate performs poorly, the profit equations are identical to those in equations (9), (10), and (11) when follow-on investment is prohibited.

When real estate performs well and the inequality in equation (4) holds for $n_{1}=0$, the intrinsic value of shares exceeds the offer price and follow-on investors buy shares. Perfectly competitive follow-on investors 
continue to invest provided that the intrinsic value of the next share purchased exceeds the fixed offer price. That is:

$$
n_{1} p_{1}^{*}>n_{1} p_{0}
$$

Differentiating the intrinsic value of shares given by equation (2) with respect to $\mathrm{n}_{1}$, we obtain:

$$
\frac{\partial p_{1}^{*}}{\partial n_{1}}=-\frac{[r(1-f)-d] n_{0} p_{0}}{\left(n_{0}+n_{1}\right)^{2}}\left\{\begin{array}{l}
<0 \text { for } r \geq \frac{d}{1-f} \\
>0 \text { for } r<\frac{d}{1-f}
\end{array}\right.
$$

When the inequality in equation (4) holds for $n_{1}=0, r \boldsymbol{S}-$ and the intrinsic value of shares declines as the number of shares bought by follow-on investors increases. Taken together, equations (12) and (13) imply that follow-on investors continue to buy shares until the intrinsic value of shares equals the offer price:

$$
p_{1}^{*}\left(n_{1}\right)=p_{0}
$$

Using equations (2) and (14), we solve for $n_{1}$ :

$$
n_{1}=\left[\frac{r_{1}-d}{f}-(1+r)\right] n_{0}
$$

Finally, substituting equation (15) into equations (6) and (8), we obtain relations describing follow-on investors' and long-term investors' profits when the inequality in equation (4) holds:

$$
\begin{gathered}
\pi_{F}=0, \text { and } \\
\pi_{L}^{\prime \prime}=n_{0} p_{0} d>0 .
\end{gathered}
$$

The expected profit to long-term investors can be computed using equations (4), (10), and (17):

$$
E\left[\pi_{L}^{\prime \prime}\right]=\int_{\underline{r}}^{\frac{f+d}{1-t}} n_{0} p_{0}[(1+r)(1-f)-1] g(r) d r+\int_{\frac{t+d}{1-f}}^{\bar{r}} n_{0} p_{0} d g(r) d r
$$


Substituting in the values from the numerical example into equation (18), the expected payoff to long-term investors is $E\left[\pi_{L}^{\prime \prime}\right]=\$ 66.67$, which translates to a 6.67 percent expected return on their $\$ 1,000$ initial investment. Recognize that long-term investors' expected profit is less than when followon investment is prohibited: $E\left\lfloor\pi_{L}^{\pi}\right\rfloor=\$ 66.67<E\left\lfloor\pi_{L}^{\prime}\right\rfloor$ The difference, $E\left[\pi_{L}^{\prime \prime}\right]_{u}-E\left[\pi_{L}^{\prime}\right]=-\$ 170.83$, represents the money long-term investors expect to forfeit to the selling, service, and acquisition fees charged by unlisted REIT affiliates and soliciting dealers on sales of shares to follow-on investors. These expected fees are equal to:

$$
E\left[\pi_{L}^{\prime \prime}-\pi_{L}^{\prime}\right]=\int_{\frac{i+d}{1-f}}^{\bar{r}} n_{0} p_{0}[(1+r)(1-f)-(1+d)] g(r) d r,
$$

creating an incentive for unlisted REIT affiliates and soliciting dealers to perpetuate the fixed-offer-price feature, despite any negative effects on longterm investors.

Figure 3 shows long-term investors' return under perfectly competitive follow-on investment, $\pi_{L} / n_{0} p_{0}$, as a function of the realized real estate return, $r$. The slope is $(1-f)=90$ percent for $r \leq f+d / 1-f=$ 31.1percent, implying that after deducting initial fees, long-term investors participate fully when real estate performs poorly. However, the slope is zero for $r>f+d / 1-f=31$.1percent, meaning that long-term investors do not participate beyond their contractual dividend when real estate performs well. The maximum periodic return that long-term investors can hope for is $d=18$ percent, the cumulative dividend paid by the unlisted REIT. The return in excess of the dividend, represented by the shaded area, is transferred from long-term investors to unlisted REIT affiliates and soliciting dealers in the form of fess paid on sales of shares to follow-on investors. Thus, follow-on investment creates a return asymmetry for long-term investors. When real estate performs poorly, long-term investors participate fully in the losses, but when real estate returns are strongly positive, long-term investors do not participate in gains beyond dividends promised by the unlisted REIT. 
Figure 3: Long-term investor return with perfectly competitive investment

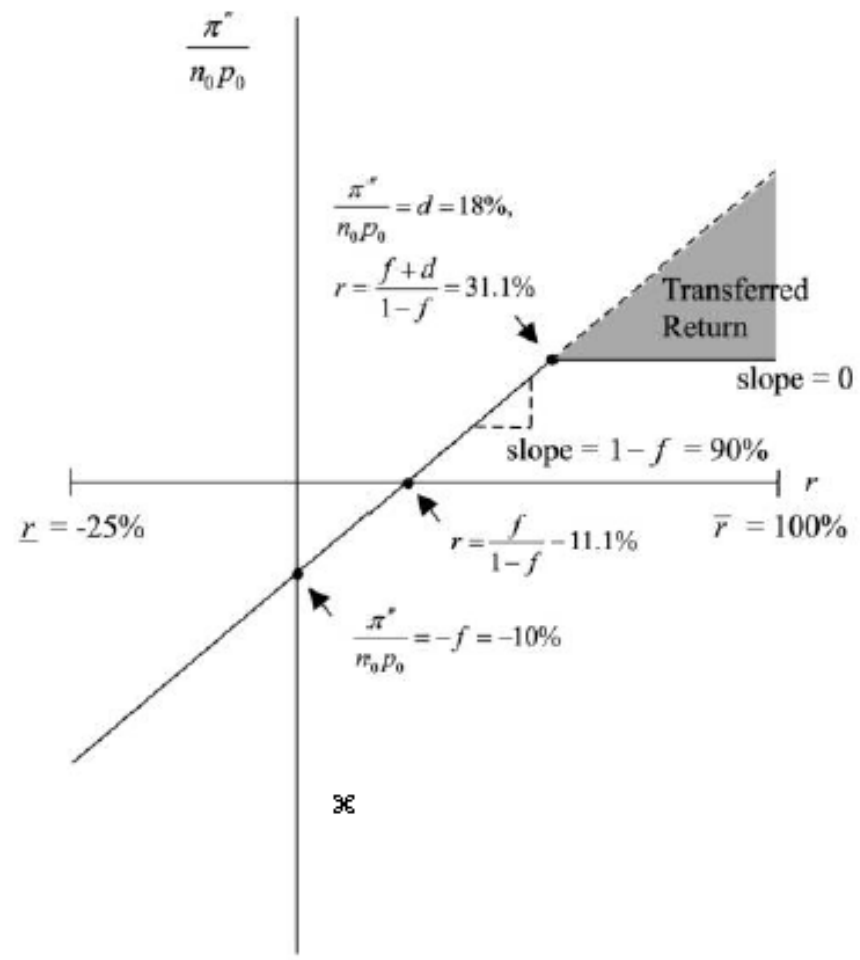

Notes: In the case of perfectly competitive investment, long-term investors' return,

$$
\frac{\pi_{L}^{\prime}}{n_{\mathrm{o}} p_{0}}=\left\{\begin{array}{cr}
(1+r)(1-f)-1 & \text { for } r \leq \frac{f+d}{1-f} \\
d \quad \text { for } r & >\frac{f+d}{1-f}
\end{array}\right.
$$

is generated by realized real estate return, $r$. The graph reflects the following parameter values: $n_{0}=100$ shares, $p_{0}=\$ 10.00, f=10 \%, d=18 \%, \underline{r}=-25 \%$, and $\bar{r}=100 \%$

\subsection{Dividends and wealth transfer}

The level of the dividend yield plays a significant role in determining the magnitude of the wealth transfer from long-term investors to unlisted REIT affiliates and soliciting dealers. Focusing on the differential impact of the dividend on the wealth transfer, we take the partial derivative of equation (19) with respect to $d$ and obtain: 


$$
\frac{\partial E\left[\pi_{L}^{\prime \prime}-\pi_{L}^{\prime}\right]}{\partial d}=n_{0} p_{0}\left(\frac{f+d}{1-f}-\bar{r}\right) g(r)<0 \text { for } \bar{r}>\frac{f+d}{1-f} .
$$

Equation (20) implies that the wealth transfer decreases as the dividend increases. To see how the dividend affects the magnitude of the wealth transfer, consider the shaded area in Figure 3. As we increase the dividend from the 18 percent in our numerical example, the inflection point moves up and to the right and the shaded area becomes smaller. If, for example, we increase the dividend yield from 18 to 24 percent, the expected wealth transfer given by equation (19) decreases from $\$ 170.83$ to $\$ 139.38$ and long-term investors' expected profit given by equation (18) increases from $\$ 66.67$ to $\$ 98.12$. Increasing the dividend further to 30 percent decreases the expected wealth transfer to $\$ 111.11$ and increases long-term investors' expected profit to $\$ 126.39$. The fixed-price feature of the unlisted REIT structure thus creates perverse dividend policies. Specifically, the longterm investors' losses can be mitigated by relatively high contractual dividends. We discuss our model's dividend implication and the empirical evidence in the next section.

\section{Empirical evidence of dividend policy distortion}

In this section we provide evidence that the unlisted REIT structure leads to perverse dividend policies. These policies produce dividends well above comparable listed REITs and, more importantly, in excess of 100 percent of FFO. All data come from SNL Securities and cover the three-year period 2003 through 2005[9]. Prior to 2003, the unlisted REIT data were not considered adequate to form broad enough cross-sections by firm size and property type. Table III presents the sample of 11 unlisted REITs. All of these companies were started after 1995 and represent every major property type. Total asset size ranges from well under $\$ 1$ billion to $\$ 8$ billion. Unfortunately, dividend information is not available for all unlisted REITs during each year.

The comparative analysis of unlisted REIT and listed REIT dividend dividends during the sample period begins with the formation of four shadow portfolios. The first portfolio (i.e. sector portfolio) consists of 41 listed REITs spanning every property type represented in the unlisted REIT sample. The firms were selected to achieve a balance by asset size. A list of these REITs and the REITs placed in other shadow portfolios appears in Table IV. To 
eliminate age bias, a second shadow portfolio (i.e. IPO portfolio) was formed that includes 23 firms with IPOs after 1996. This portfolio also is balanced by property type and asset size. Finally, we assembled two similarly balanced portfolios of differing sizes (i.e. small size and large size). The small size portfolio has 17 REITs with NAVs falling in the range of $\$ 400$ million to $\$ 700$ million and the large size portfolio consists of 30 firms with NAVs ranging from $\$ 1.2$ billion to $\$ 3$ billion.

Table $\mathrm{V}$ provides comparisons of average dividend payout as a percent of FFO across the unlisted and listed REIT portfolios during 2003, 2004, and 2005. The

Table III: Unlisted REIT sample

\begin{tabular}{|c|c|c|c|c|}
\hline \multirow[b]{2}{*}{ Company name } & \multirow[b]{2}{*}{$\begin{array}{c}\text { Year } \\
\text { established }\end{array}$} & \multirow[b]{2}{*}{ Sector } & \multicolumn{2}{|c|}{2005} \\
\hline & & & $\begin{array}{c}\text { Total assets } \\
(\$ 000)\end{array}$ & $\begin{array}{l}\text { Regular } \\
\text { dividend }\end{array}$ \\
\hline 1. Apple Hospitality Five, Inc. & 2001 & Hotel & $\$ 413,447$ & $\$ 0.88$ \\
\hline 2. Apple Hospitality Two, Inc. & 2001 & Hotel & $\$ 638,176$ & $\$ 0.80$ \\
\hline 3. Berkshire Income Realty, Inc. & 2002 & Multifamily & $\$ 425,662$ & $\$ 0.00$ \\
\hline 4. CNL Hotels \& Resorts, Inc. & 1996 & Hotel & $\$ 5,688,782$ & $\$ 1.10$ \\
\hline 5. CNL Retirement Properties, Inc. & NA & Health care & $\$ 3,838,761$ & $\$ 0.71$ \\
\hline 6. Dividend Capital Trust, Inc. & 2002 & Industrial & $\$ 2,057,695$ & $\mathrm{NA}$ \\
\hline 7. G REIT, Inc. & 2001 & Office & $\$ 887,499$ & $\$ 0.75$ \\
\hline 8. Inland Retail Estate, Inc. & NA & Retail & $\$ 4,268,088$ & $\mathrm{NA}$ \\
\hline 9. Inland Western Retail Estate Trust, Inc. & NA & Retail & $\$ 8,085,933$ & $\$ 0.64$ \\
\hline 10. T REIT, Inc. & 1998 & Office & $\$ 48,322$ & NA \\
\hline 11. Wells Real Estate Investment Trust, Inc. & 1998 & Office & $\$ 4,398,565$ & $\$ 0.61$ \\
\hline
\end{tabular}

Note: This table presents a list of 11 unlisted REITs and selected characteristics as reported by SNL Securities

Source: SNL Securities

dividend payout ratios for listed REITs fall within a normal range for REITs of between 60 and 75 percent (Farrell, 2006). Average payout ratios for the sample of unlisted REITs not only exceeded those of listed REITs by a sizeable margin, but were greater than 100 percent during all three years. This means that unlisted REITs paid out more in dividends than they received in cash flow over a three year period. Logic dictates that such a perverse dividend policy is unsustainable. 


\section{Conclusion}

The idea to provide Federal tax-exempt status to business trusts that invest in commercial real estate became law in 1960 due to the efforts of a diverse group of special industry and government interests (Lynn and Bloomfield, 2003). Beyond the motivations of these groups to increase capital flows for real estate investment and rehabilitation was the intent of making available to retail investors certain advantages previously reserved for investors with greater resources. These advantages include diversification through pooling of funds, access to the benefits of professional investment advisors, and the ability to collectively finance properties of a scale that most individual investors could not undertake by themselves (Fass etal, 2004). As the REIT market matured, firms became larger and more public. Average investors seeking these opportunities had to enter the public securities environment, which they may neither find familiar nor trust.

Recognizing that a segment of the retail investor population was not comfortable with prevailing commercial real estate investment options, sponsors of unlisted REITs reached retail investors through existing brokerdealer channels to provide an alternative way of accessing institutional grade real estate portfolios. The programs of unlisted REIT sponsors, therefore, directly align with the spirit of the original US REIT legislation. In addition, these programs demonstrated substantial appeal as evidenced by the amount of capital flowing to unlisted REIT sponsors during recent years through broker-dealer networks. 


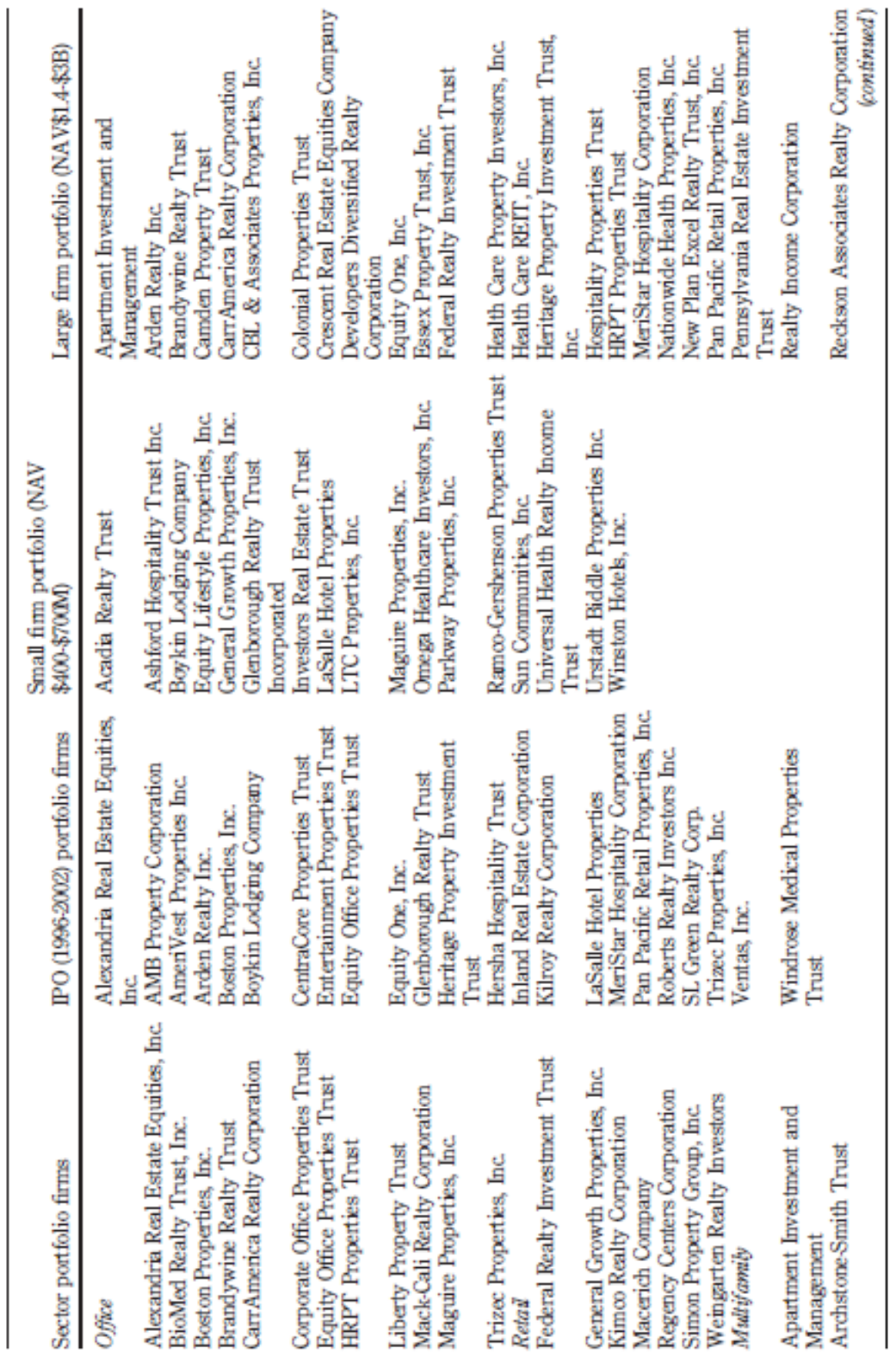




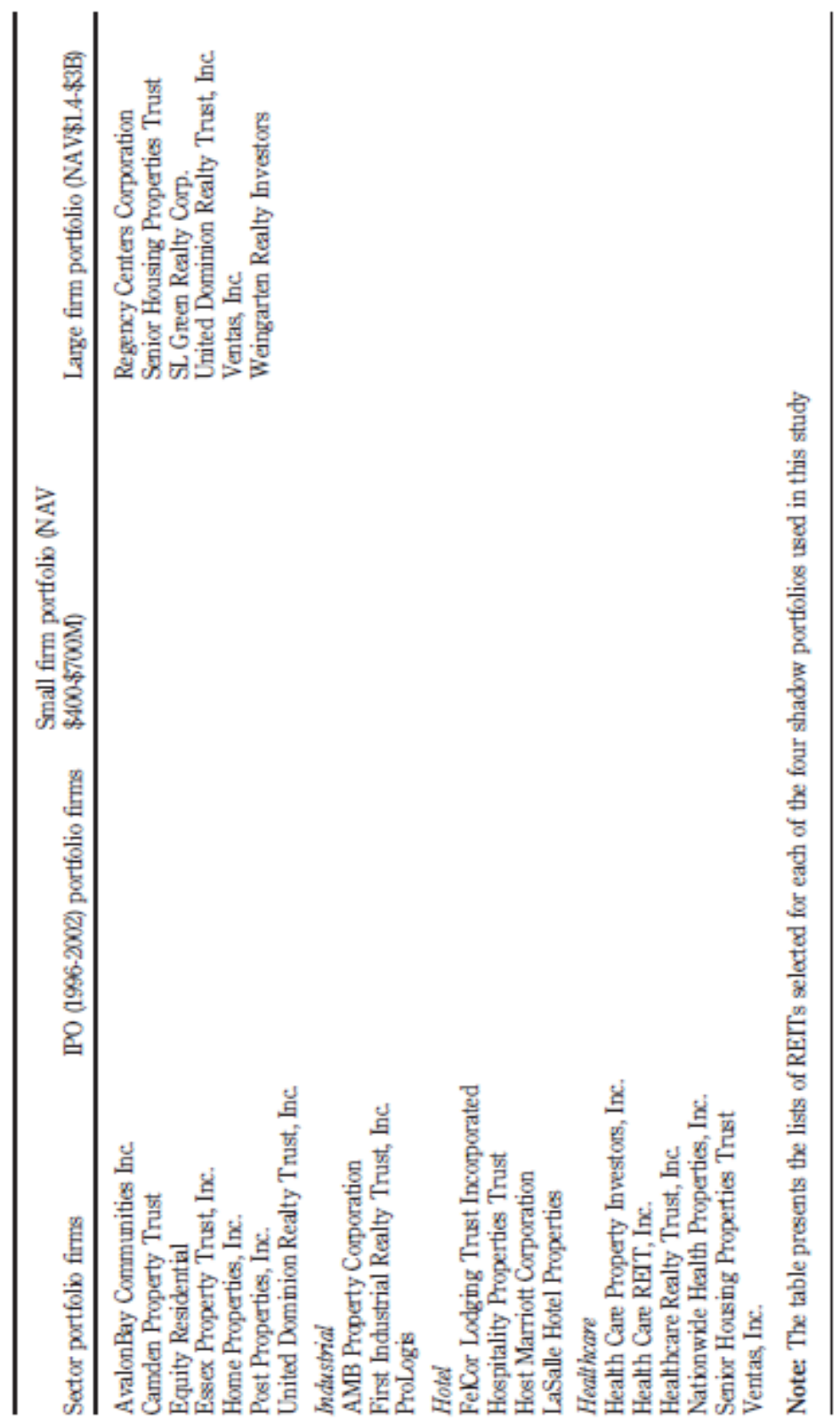


During the initial phase in the maturation of unlisted REITs, critics emphasized the size of the fees earned by participants in the broker-dealer network and the integrity of sponsors. As market conditions change, investors' holding periods lengthen, and the exit strategies of unlisted REITs come to fruition, closer scrutiny is being directed to more general problems, such as conflict-of-interest issues and structural problems of the investment programs. In this paper we identify one structural flaw present in unlisted REIT investment programs - the fixed share price. Our model provides a mechanism for analyzing the consequences of fixed share prices on fees generated through the broker-dealer network and the profits and returns received by both long-term (i.e. those who invest early) and opportunistic follow-on (i.e. those who enter late) investor groups.

The model solutions using a fixed share price assumption provide several insights. First, opportunistic follow-on investors participate only during up real estate markets as the intrinsic values of shares rise above fixed share prices. Second, during periods of rising property values and with perfectly competitive capital markets, follow-on investors will buy shares as long as intrinsic share value exceeds fixed share price, driving long-term investors' profit to the level of dividends. Profits in excess of dividends are absorbed by participants in the broker-dealer network. Third, a high contractual dividend level can be used to mitigate the wealth transfer from long-term investors. A comparative analysis of the dividend payout behaviors of listed and unlisted REITs during recent years reveals that unlisted REITs have paid dividends relative to FFO well in excess of listed REITs and also approximately 110 percent of their own FFOs. This perverse dividend policy follows from the fixed-share price structure adopted by these firms.

The basic structure of unlisted REITs has many desirable features and should be preserved, but with modification to the fixed share price feature to limit investor conflicts. A convenient parallel to unlisted REIT unit investment in commercial real estate is the commingled fund (see Fosheim, 1995). Ennis (1996) describes the institutional arrangement as follows:

In a straightforward process each asset in the commingled fund is appraised periodically. The value of the properties are then added together to arrive at the value for the fund. As properties change in value, the fund value is adjusted. Commingled fund values are quoted as if the properties were sold at appraised value (at least on average across the properties in the fund)... Intrinsic value is determined only 
by the asset appraisal methodology controlled by the fund manager (p. 36).

Table V: Dividend payouts of unlisted REITs and shadow portfolios of listed REITs, 2003-2005

\begin{tabular}{lccccc}
\hline & Unlisted REIT & Sector & IPO date & Small size & Large size \\
\hline Number of REITs & 11 & 41 & 23 & 17 & 30 \\
FFO payout ratio 99 & & & & & \\
2005 & 106.04 & 73.12 & 71.32 & 66.06 & 76.02 \\
2004 & 125.45 & 73.74 & 70.71 & 61.51 & 75.03 \\
2003 & 114.11 & 73.01 & 67.73 & 70.90 & 76.23
\end{tabular}

Note: This table shows average dividend payout as a peroent of FFO for the sample of 11 unlisted REITs and four shadow portfolio samples

Source: SNL Securities

Analysts following publicly-traded REITs use simpler and less costly NAV calculations (relative to appraisals) to mark the values of REIT assets to market. Regardless of the approach taken, the unlisted REIT business model needs adjustment to avoid the undesirable consequences arising from fixed offer pricing.

\section{Notes}

1. The private REIT category includes a variety of different types of companies whose sponsors elect REIT status. Many of these companies are small, do not rely on broker-dealer networks to raise capital, and do not register with the SEC. Unlisted REITs represent a special category of private REITs. These companies satisfy SEC reporting requirements as if the shares are publicly traded and rely more heavily than other non-traded REITs on broker-dealer networks. In most instances, unlisted REIT sponsors choose this mode of operation to prepare for an IPO or exchange listing in the future. One of the large unlisted REITs, inland (IRC), listed during 2004 and another firm, CNL hospitality, had an unsuccessful IPO during 2004.

2. During the five-year period ending in December 2003, unlisted REITs raised $\$ 13$ billion of equity while publicly-traded REITs raised $\$ 22$ billion. The majority of the sales of unlisted REIT shares were by a few of these companies, such as CNL and Wells.

3. For an overview of TIC investment, see Napoli (2005). 
4. Inland, for example, initially offered shares at $\$ 10$ then raised the price to $\$ 11$. Within months after trading began in June 2004, the shares of Inland stabilized at an approximate price of $\$ 16$.

5. Reviews of the REIT literature by Corgel et al. (1995) and a recent update by Zietz et al. (2003) contain no mention of unlisted REITs.

6. Among other actions taken in preparation for exchange listing, unlisted REITs may convert from externally managed to internally managed companies.

7. The REIT Modernization Act of 1999 changed the dividend requirement to 90 percent of taxable income beginning in 2001 from the previous requirement of 95 percent. Some listed REITs payout more than 100 percent of taxable income, but typically do not payout more than 70 percent of FFO.

8. For a recent study of dividend taxes and corporate valuations that controls for exogenous factors through the use of REIT data (see Gentry et al., 2003).

9. As mentioned earlier, unlisted follow SEC reporting requirements despite not having publicly traded stock. Hence SNL is able assemble data on these firms to track their performance.

\section{References}

Bradley, M., Capozza, D.R. and Seguin, P.J. (1998), "Dividend policy and cashflow uncertainty", Real Estate Economics, Vol. 26 No. 4, pp. 555-80.

Corgel, J.B., Mclntosh, W. and Ott, S.H. (1995), "Real estate investment trusts: a review of the financial economics literature", Journal of Real Estate Literature, Vol. 3 No. 1, pp. 13-43.

Ennis, J.L. (1996), “Real estate commingled fund valuation: disconnected from the public markets", Real Estate Finance, Vol. 12, pp. 36-41.

Farrell, C. (2006), "Private REITs dividend draw”, Business Week, February 13.

Fass, P.M., Shaff, M.E. and Zief, D.B. (2004), Real Estate Investment Trust Handbook, Thompson West, Eagan, MN.

Fitch, S. (2003), "Blind faith", September 1, available at: www.Forbes.com. 
Fosheim, J. (1995), "Private REITs: co-mingled funds with a new name", Green Street Advisors, special report, August.

Gentry, W.M., Kemsley, D. and Mayer, C.J. (2003), “Dividend taxes and share prices: evidence from real estate investment trusts", Journal of Finance, Vol. 58, February, pp. 261-82.

Ghosh, C. and Sirmans, C.F. (2006), "Do managerial motives impact dividend decisions in REITs", Journal of Real Estate Finance and Economics, Vol. 32 No. 2, pp. 327-55.

Johnson, B. (2003), "Let's set the record straight on unlisted REITs success", letter to the editor, National Real Estate Investor, September 1.

Lynn, T.S. and Bloomfield, M. (2003), Real Estate Investment Trusts, Thompson West, Eagan, MN.

Napoli, M. (2005), "TIC business booms", Real Estate Forum, February.

Ostrowski, C. (2004), "The REIT wars", Real Estate Forum, May, pp. 60-6.

Smith, R.A. (2003a), "Private commercial REITs get into the game", Wall Street Journal, February 19, p. B12.

Smith, R.A. (2003b), "Questions-and-answers-about private REITs", Wall Street Journal, March 19, p. B8.

Zietz, E.N., Sirmans, G.S. and Friday, H.W. (2003), "The environment and performance of real estate investment trusts", Journal of Real Estate Portfolio Management, Vol. 9 No. 2, pp. 127-65.

\section{Corresponding author}

John Corgel can be contacted at: jc81@cornell.e 